\title{
Dietary gluten and the development of type 1 diabetes
}

\author{
Julie C. Antvorskov • Knud Josefsen • Kåre Engkilde • \\ David P. Funda $\cdot$ Karsten Buschard
}

Received: 4 December 2013 / Accepted: 9 April 2014 / Published online: 29 May 2014

(C) The Author(s) 2014. This article is published with open access at Springerlink.com

\begin{abstract}
Gluten proteins differ from other cereal proteins as they are partly resistant to enzymatic processing in the intestine, resulting in a continuous exposure of the proteins to the intestinal immune system. In addition to being a diseaseinitiating factor in coeliac disease (CD), gluten intake might affect type 1 diabetes development. Studies in animal models of type 1 diabetes have documented that the pathogenesis is influenced by diet. Thus, a gluten-free diet largely prevents diabetes in NOD mice while a cereal-based diet promotes diabetes development. In infants, amount, timing and mode of introduction have been shown to affect the diabetogenic potential of gluten, and some studies now suggest that a gluten-free diet may preserve beta cell function. Other studies have not found this effect. There is evidence that the intestinal immune system plays a primary role in the pathogenesis of type 1 diabetes, as diabetogenic $T$ cells are initially primed in the gut, islet-infiltrating $\mathrm{T}$ cells express gut-associated homing receptors, and mesenteric lymphocytes transfer diabetes from NOD mice to NOD/severe combined immunodeficiency (SCID) mice. Thus, gluten may affect diabetes development by influencing proportional changes in immune cell populations or by modifying the cytokine/chemokine pattern towards an inflammatory profile. This supports an important role for gluten intake in the pathogenesis of type 1 diabetes and further studies should be initiated to clarify whether a gluten-free diet
\end{abstract}

J. C. Antvorskov $(\bowtie) \cdot K$. Josefsen · K. Engkilde • D. P. Funda • K. Buschard

The Bartholin Institute, Rigshospitalet, Ole Maaløes Vej 5, section 3733, Copenhagen, Denmark

e-mail: julie.antvorskov@gmail.com

D. P. Funda

Department of Immunology and Gnotobiology, Institute of Microbiology, Academy of Sciences of the Czech Republic, Prague, Czech Republic could prevent disease in susceptible individuals or be used with newly diagnosed patients to stop disease progression.

Keywords Coeliac disease · Diet · Gluten · Gluten-free . Type 1 diabetes

$\begin{array}{ll}\text { Abbreviations } \\ \text { APC } & \text { Antigen-presenting cell } \\ \text { BB } & \text { BioBreeding } \\ \text { CD } & \text { Coeliac disease } \\ \text { DAISY } & \text { Diabetes Autoimmunity Study in the Young } \\ \text { DC } & \text { Dendritic cell } \\ \text { FOXP3 } & \text { Forkhead box P3 } \\ \text { GALT } & \text { Gut-associated lymphoid tissue } \\ \text { MLN } & \text { Mesenteric lymph nodes } \\ \text { MyD88 } & \text { Myeloid differentiation factor } 88 \\ \text { NK } & \text { Natural killer } \\ \text { PLN } & \text { Pancreas-associated lymph nodes } \\ \text { SPF } & \text { Specific-pathogen-free } \\ \text { Th } & \text { T helper } \\ \text { TLR } & \text { Toll-like receptor } \\ \text { tTG } & \text { Tissue transglutaminase }\end{array}$

\section{Type 1 diabetes and coeliac disease}

Type 1 diabetes incidence has increased over the last two decades, especially in children under the age of 5 [1]. Type 1 diabetes is a multifactorial disease in which the genetic background is essential, but not sufficient for causing the disease. Type 1 diabetes incidence has been rising more rapidly than can be accounted for by genetic changes, thus emphasising the influence of environmental factors [2]. Different environmental factors could play a role in type 1 
diabetes susceptibility: cereal proteins, cow's milk proteins, low vitamin D, enteroviruses, changes in the composition of gut microbiota and stressful life events. Further, the 'hygiene hypothesis' suggests that exposure to a large number of infections early in life prevents the development of autoimmunity through appropriate priming of the adaptive immune system [3] (Fig. 1).

Coeliac disease (CD) is an inflammatory intestinal disease with autoimmune features triggered by exposure to dietary gluten and related cereal proteins. The proteins induce an inflammatory immune response in the intestine; their withdrawal results in disease remission. The intestinal inflammation can result in complete destruction of the intestinal epithelium with crypt hyperplasia, loss of the villous structure and infiltration of lymphocytes, with consequent malabsorption of nutrients, vitamins and minerals [4]. Screening studies indicate that $\mathrm{CD}$ has a high prevalence $(\approx 1 \%)$ in many Western countries and that a large group of people have undetected CD, which has led to the concept of a 'coeliac iceberg', depicting different undiagnosed, silent forms of CD [5].

The pathogenesis is initiated when gluten peptides cross the intestinal epithelium. The peptides can be deamidated or crosslinked by the enzyme tissue transglutaminase (tTG). Deamidation introduces a negative charge into the gluten peptides, increasing their binding affinity to HLA-DQ2 or HLA-DQ8 on antigen-presenting cells (APCs), and thereby increasing the possibility of reaching the threshold required to prime gluten-reactive $\mathrm{T}$ cells. The intestinal $\mathrm{CD}^{+} \mathrm{T}$ cell response is directed against many different epitopes in the gluten proteins. However, the T cell epitopes tend to cluster in proline-rich regions of the gluten proteins [4]. Of particular interest is the observation that nearly all $\mathrm{T}$ cell lines from adult CD patients recognise the same 33-mer gliadin peptide. It contains six HLA-DQ2-binding and T cell-stimulatory epitopes and is resistant to intestinal digestion [6]. CD is moreover characterised by IgA and IgG autoantibodies directed against tTG, by intestinal activation of T helper (Th)17 cells, $\mathrm{CD}^{+}$T cells, $\gamma \delta \mathrm{T}$ cells, natural killer (NK) cells and dendritic cells (DCs) [7-9], and by the direct effect of gluten on intestinal enterocytes [10].

\section{The association between $C D$ and type 1 diabetes is well established}

Type 1 diabetes and CD share a similar genetic background, with high susceptibility associated with the HLA-DQ2/DQ8 genotype. Several other genes are also implicated in susceptibility to both diseases, while up to 15 risk alleles contribute to both diseases [11]. This is at least part of the explanation as to why there is a high prevalence of patients with both diseases. Thus, studies have revealed an average CD prevalence of $2-$ $12 \%$ among children with type 1 diabetes $[12,13]$, and among patients diagnosed with both type 1 diabetes and $\mathrm{CD}$, the majority of the patients were diagnosed with type 1 diabetes before $\mathrm{CD}$, probably due to the diabetes-protective effect of a gluten-free diet [14].

\section{Dietary gluten}

The taxonomic relationship of cereals classifies them into different subfamilies, where wheat, rye and barley are in the same tribe. Wheat has highly viscoelastic properties, which allow dough to form when wheat flour is mixed with water. This viscoelastic network is called gluten. The major components of gluten are storage proteins called prolamins, which can be separated into two groups: gliadins $(\alpha-, \gamma-$ and $\omega$-gliadin) and glutenins. The prolamin storage proteins in wheat, rye and barley differ from other cereals' storage proteins in the following ways (Table 1): they are present in higher amounts, have a higher molecular mass and contain higher proportions of proline and glutamine. Finally, the
Fig. 1 Dietary gluten affects the development of type 1 diabetes. The influence of genetic predisposition, different environmental factors and dietary gluten on disease pathogenesis. Type 1 diabetes is a multifactorial disease, the development of which is dependent on genetic as well as environment factors, which alone or together affect immune balance, resulting either in protection against or susceptibility to disease development

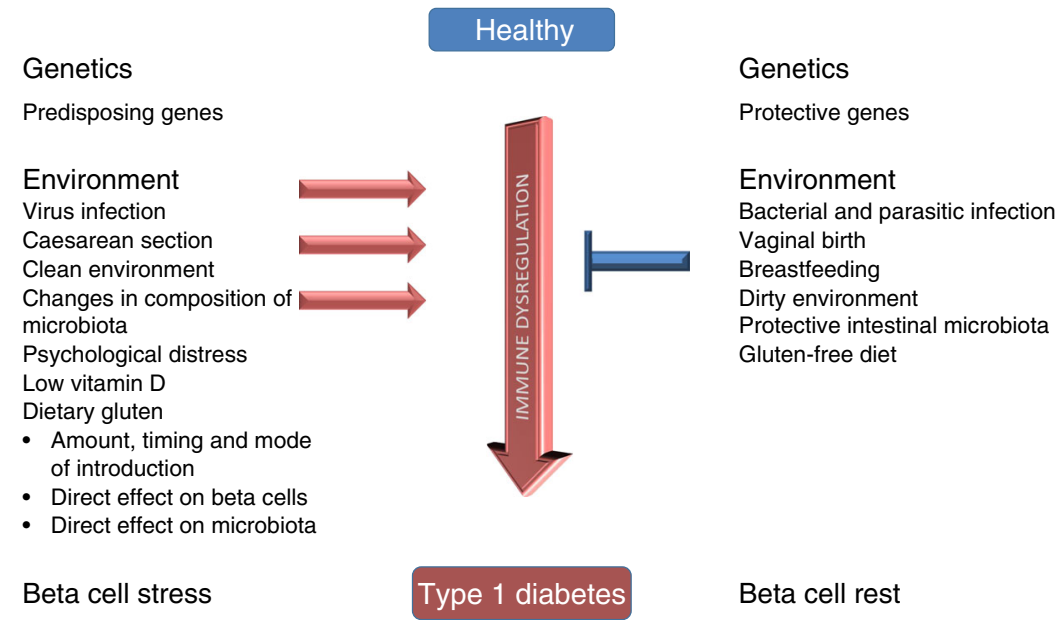


Table 1 Gluten proteins differ from other cereal proteins

\begin{tabular}{lll}
\hline Property & Wheat, rye, barley & $\begin{array}{l}\text { Other cereals (e.g. oats, } \\
\text { rice, maize) }\end{array}$ \\
\hline Level of prolamins & $40-50 \%$ & $10 \%$ (in oats) $^{\mathrm{a}}$ \\
Molecular mass & $30-90 \mathrm{kDa}$ & $10-16 \mathrm{kDa}($ in rice) \\
Amino acid sequence & $\uparrow$ Proline & $\uparrow$ Leucine \\
& $\uparrow$ Glutamine & $\uparrow$ Alanine (in maize) \\
Repeats & PQQPFPQQ & VLPA or FNQLA \\
& $(90 \%)$ & $(25 \% \text { in maize })^{\mathrm{a}}$ \\
\hline
\end{tabular}

${ }^{\text {a }}$ Representative for non-gluten-containing cereals

prolamins in wheat, rye and barley are insoluble in water, because of the presence of highly hydrophobic repeated sequences $[15,16]$.

Thus, the storage proteins in wheat, rye and barley have several properties that distinguish them from other cereal proteins. So far, most studies have focused on the gliadins and glutenins of wheat gluten, but because of the similar structures of rye and barley, many of the results can also be applied to these cereals.

\section{Gluten peptides show resistance to enzymatic processing in the intestine}

The normal digestive breakdown of dietary proteins ensures that peptides are efficiently hydrolysed into amino acids and di- or tripeptides before they are transported across the intestinal epithelium. This process ensures that the proteins are rendered harmless, because di- and tripeptides cannot initiate an adaptive immune response. As mentioned, the amino acid sequences of gluten and related proteins from rye and barley are very rich in proline residues, which render them resistant to enzymatic processing at two levels: at the gastric/pancreatic level and at the brush-border peptidase level [17]. The slow cleavage rate implies that there could be an intestinal, luminal accumulation of gliadin peptides following a glutencontaining meal. In vitro experiments showed that prolonged treatment of intact $\alpha 2$-gliadin with gastric and pancreatic enzymes and brush-border membrane fractions resulted in a stable proteolytic fragment, the 33-mer peptide (LQLQPFPQPQLPYPQPQ-LPYPQPQLPYPQPQPF). While control dietary peptides were rapidly proteolysed, the 33-mer peptide remained intact. Homologue sequences to the 33-mer were found in rye and barley, but not in oats or other cereals [6]. Thus, proteins from wheat, rye and barley can be expected to be comparably resistant to proteolysis. Ingestion of gluten is therefore likely to result in sustained, high intestinal concentrations of non-degradable gluten peptides.

\section{Gluten and the intestinal microbiota}

It has been reported that microbial enzymes are capable of degrading gluten proteins [18]. Data suggest that CD patients have higher levels of gliadin-metabolising enzymes with bacterial origin than do healthy controls. It has been suggested that gliadin proteolysis by intestinal bacteria could initiate $C D$, due to the formation of immunogenic gluten peptides [19]. The possible involvement of the intestinal microflora in the pathogenesis of $\mathrm{CD}$ is supported by studies showing that $\mathrm{CD}$ patients exhibit changes in the composition of the duodenal microbiota of the gut [20]. On the other hand, intragastric application of gluten to AVN rats (an animal model of CD) at birth induced features of gluten enteropathy [21]. Such results were also reproducible in germ-free rats, suggesting direct activation of intestinal immune responses by gluten proteins [22].

Observations that specific-pathogen-free (SPF) animal facilities (e.g. positively defined SPF microflora, such as altered Schaedler microflora), antibiotic decontamination and re-derivation of the breeding nucleus facilitate high diabetes incidence in NOD mice, show the role of intestinal microflora in type 1 diabetes development [23]. An early study in BioBreeding (BB) rats documented that treatment with fusidic acid [24] and vancomycin [25], both antibiotics against Gram-positive bacteria, reduce diabetes incidence. Heat-killed Lactobacillus casei fed to NOD mice also prevented development of diabetes [26]. Thus, clean conditions seem to increase type 1 diabetes incidence, whereas infections (including parasites) and administration of bacterial components decrease the development of the disease. Wen et al have further documented higher diabetes incidence in germ-free mice compared with SPF-reared NOD mice and have described possible innate immune mechanisms involved in the disease processes [27]. These data indicate that commensal microflora have a modifying, disease-preventive effect on type 1 diabetes.

Gluten intake directly affects the composition of the intestinal microflora, as NOD mice fed a gluten-free diet have reduced numbers of caecal bacteria and Gram-positive bacteria compared with mice fed a standard diet containing wheat proteins [28]. In a recent study by Marietta et al, a glutencontaining diet specifically increased Bifidobacterium, Tannerella and Barnesiella species, whereas Akkermansia was increased in the intestinal microflora of NOD mice fed a gluten-free diet [29].

Both intestinal microflora and diet influence penetration of type 1 diabetes in the animal models. When certain diabetespreventive diets were first tested in gnotobiotic (microfloradefined) or germ-free conditions, it was revealed that microbiota-independent mechanisms are responsible for the protective effects of these diets; however, other diets (e.g. 
hydrolysed casein-based formula) have been found to have a microbiota-dependent diabetes-protective effect (D. P. Funda, unpublished results). Patrick et al showed that a diet based on cereals was a stronger promoter of type 1 diabetes than gut microbes; thus, a more significant protection from disease development was observed by feeding a hydrolysed caseinbased diet than could be obtained by altering the microbiota [30]. More studies in germ-free and gnotobiotic animals are needed to clarify the mechanisms and the interplay between different dietary (not specifically gluten) and microbial factors in type 1 diabetes prevention, and to determine which diet-induced changes to the composition of commensal microflora have causative effects on the pathogenesis of type 1 diabetes.

\section{Dietary gluten influences the development of type 1 diabetes}

Evidence of the interplay between ingested gluten and the subsequent development of type 1 diabetes has been revealed by studies in humans and animals.

In 1999 we demonstrated that a gluten-free, nonpurified diet largely prevented diabetes onset in NOD mice, as following a gluten-free diet for 320 days reduced the incidence of diabetes from $64 \%$ in control mice to $15 \%$ in mice on the gluten-free diet [31] with a further incidence reduction to $6 \%$ in mice never exposed to gluten either in the uterus or in diet [32]. The highest incidence of type 1 diabetes in experimental animal models is found in animals on a wheat-based diet [33], and a cereal-based diet promotes type 1 diabetes development in both NOD mice and BB rats [34, 35]. This suggests a clear correlation between gluten intake and increased diabetes susceptibility.

In a preliminary study in humans, the autoantibody titres did not show significant changes in response to a gluten-free diet. However, the insulin response in a glucose tolerance test increased in 12 out of 14 patients on the gluten-free diet. After returning to a normal diet, the acute insulin response decreased in ten out of 13 patients. Furthermore, insulin sensitivity, measured as HOMA-IR, improved on the gluten-free diet and subsequently decreased after 6 months back on the normal diet [36]. The effect of a gluten-free diet for 1 year was also investigated in seven children predisposed to type 1 diabetes who tested positive for beta cell autoantibodies. The gluten-free diet did not influence the autoantibody titres [37]. This is in contrast to a recently reported study of a 5-year-old boy diagnosed with classical type 1 diabetes without CD. The patient was introduced to a gluten-free diet, resulting in a reduction in $\mathrm{HbA}_{1 \mathrm{c}}$ from $7.8 \%$ to $5.8-6.0 \%$ without insulin therapy. Fasting blood glucose was maintained at $4.0-5.0 \mathrm{mmol} / \mathrm{l}$. At 16 months after diagnosis the fasting blood glucose was $4.1 \mathrm{mmol} /$ 1 , and after 20 months he was still without daily insulin therapy, suggesting that the gluten-free diet prolonged remission in this patient with type 1 diabetes [38]. In studies of patients with both $\mathrm{CD}$ and type 1 diabetes, a gluten-free diet mediated clinical improvements, such as increases in weight, height, haemoglobin level, corpuscular volume and diabetic control [13, 39]. However, other studies found no effect [40, 41]. The findings indicate that a gluten-free diet may have a beneficial effect on the preservation of beta cell function in highrisk individuals. The mechanism by which gluten's removal from the diet could improve insulin secretion is, however, unclear.

The studies mentioned above investigated individuals positive for beta cell autoantibodies, which implies an already initiated immune response against the islets. However, a large human intervention trial is needed to investigate possible preventive effects of a permanent gluten-free diet in genetically predisposed individuals.

\section{A subset of type 1 diabetic patients has an abnormal immune response to gluten}

Gluten challenge has been used in CD patients to assess their mucosal immune response to gluten, but has also been used as a tool to study an abnormal immune reactivity to gluten in type 1 diabetic patients. In a study of 19 type 1 diabetic children, $20 \%$ reacted to rectal gluten challenge by lymphocyte infiltration in the epithelium and the underlying lamina propria. The patients all had HLA-haplotypes associated with CD, but normal mucosal histology and tTG antibody-negative serology [42]. Recently, it was shown that 20 out of 42 type 1 diabetic patients (tTG antibody-negative) had increased proliferative $\mathrm{T}$ cell response (peripheral blood mononuclear cells) to wheat proteins, with production of proinflammatory cytokines, such as IFN $\gamma$, IL-17A and TNF. Interestingly, this response to gluten was not explained by CD-associated haplotypes, which indicates that the proinflammatory response to wheat proteins is not only present in CD patients [43]. This study is supported by earlier findings of an increased $\mathrm{T}$ cell response to gluten in $24 \%$ of newly diagnosed type 1 diabetic patients [44]. The results show that an abnormal mucosal immune response to gluten is present in at least a subset of type 1 diabetic patients. The association may simply reflect the common genetic background of $\mathrm{CD}$ and type 1 diabetes; however, the studies reporting a specific immune response to gluten in type 1 diabetic patients without CD-associated HLA- 
haplotype suggest a direct, diabetes-specific effect of gluten.

Besides the effect of gluten proteins on the development of type 1 diabetes, other components of wheat, such as wheat storage globulin (Glo-3A), may also be associated with disease [45]. However, Glo-3A antibody levels did not differ in a recent study comparing islet-autoantibody-positive children with controls [46].

These studies support the idea that gluten, and perhaps other wheat proteins, influence the development of type 1 diabetes.

\section{The diabetogenic effect of gluten can be modified}

Several different factors affect the diabetogenic potential of gluten: the amount of ingested gluten, and the timing and mode of gluten introduction.

The dose or amount of ingested gluten was earlier found to be important in maintaining a tolerant immune response to gluten. NOD mice fed a diet four times higher in gluten content than the standard diet showed protection from type 1 diabetes at the same level as the gluten-free diet [32]. This finding is supported by studies showing dose-dependent effects of gluten on type 1 diabetes development in NOD mice, where high wheat concentrations returned diabetes incidence to the same level as in control mice [47].

Two prospective cohort studies (BABYDIAB and Diabetes Autoimmunity Study in the Young [DAISY]) have established a connection between the timing of early exposure to gluten and the risk of developing islet-specific antibodies. The BABYDIAB study found that children exposed to gluten-containing cereals before the age of 3 months have an increased risk (HR 4.0) of developing islet autoantibodies, compared with children who only received breast milk during the same period. Children receiving gluten after the age of 6 months did not have an increased risk of developing islet autoantibodies [48]. The DAISY study found that children exposed to both non-gluten-containing and glutencontaining cereals before the age of 3 months (HR 4.32), or after 7 months (HR 5.6), had an increased risk of islet autoimmunity compared with children first exposed to gluten between the ages of 4 and 6 months [49]. Moreover, the DAISY study showed that if cereals were introduced while the child was still being breastfed, the risk of developing islet antibodies was reduced [49]. Both studies found that early introduction of foods containing gluten or other cereals before the age of 3 months is associated with an increased risk of islet autoimmunity in childhood. This reflects that there may be a 'time window' for gluten introduction, that best allows tolerance to be achieved [50], and that the timing of the first exposure to gluten may influence overall immune tolerance to food antigens [51]. However, a delayed timing of first gluten exposure (12 vs 6 months) in infants was tried in a dietary intervention trial including 150 infants with a first-degree family history of type 1 diabetes and a risk HLA genotype. During the first 3 years of age there was no significant difference between the early and late exposure groups according to the risk for developing type 1 diabetes [52]. These results are supported by an earlier finding showing that time for gluten introduction had no influence on development of diabetes-related autoantibodies in non-diabetic children [53]. However, the latter study does not define the exact time point for gluten introduction nor does it record simultaneous breastfeeding. The importance of timing of first exposure to solid food is not only restricted to gluten exposure, as it has also been found that early introduction of root vegetables, by the age of 4 months, is associated with increased risk for beta cell autoimmunity [54], indicating that oral tolerance induction towards different food antigens could play an important role for the risk of type 1 diabetes development.

The mode of gluten introduction has also been shown to influence gluten's diabetogenic effect. The development of diabetes in BB rats is modified according to the diet they are fed during and after weaning. When gluten is introduced to BB rats after weaning, it seems to be a potent inducer of diabetes. On the other hand, if gluten is introduced early in BB rat neonates, while they are still being exposed to lactation, the diabetes incidence is significantly reduced [55]. This supports the previously mentioned result found in the DAISY study and is consistent with recent findings on the modification of gluten intake in NOD mice, where early avoidance of gluten immediately after weaning delays diabetes onset and is associated with reduced insulin autoantibodies and insulitis [56]. This implies that modifying exposure to gluten can influence its diabetogenic potential.

Moreover, the importance of amount, timing and mode of gluten introduction is supported by a study investigating differences in infant diet after an increase in the incidence of CD was observed in Sweden between 1985 and 1987. The annual incidence rate of CD in children below 2 years of age increased fourfold in this period, followed by a sharp decline to the previous level. The rise seemed to be the result of changes in the infant diet: an increase in the amount of gluten consumed, the postponement of gluten introduction from 4 to 6 months of age, and the interruption of breastfeeding when gluten was introduced [57]. The possible protection from $\mathrm{CD}$ 
[58] and type 1 diabetes associated with breastfeeding [59] could be explained by the immune-modulating effect of breastfeeding on the developing cellular immune system.

This implies that differences in gluten introduction can have an impact on gluten's diabetogenic potential, and thus, on its effect on the development of $\mathrm{CD}$ and type 1 diabetes.

\section{The intestinal immune system is involved in the pathogenesis of type 1 diabetes}

Evidence points toward the involvement of the intestinal immune system in the development of type 1 diabetes and studies suggest that pancreas-infiltrating autoreactive T cells may be activated in the gut-associated lymphoid tissue (GALT) (Text box: The intestinal immune system is involved in the pathogenesis of type 1 diabetes).

\section{The intestinal immune system is involved in the pathogenesis of type 1 diabetes}

\section{Animal studies}

Diabetogenic T cells are initially primed in the gut [65]

Islet-infiltrating $\mathrm{T}$ cells express gut-associated homing receptor [62]

Mesential lymphocytes transfer diabetes to healthy mice [64]

Prediabetic BB rats show intestinal morphological and immunological changes $[68,69,95,96]$

Diabetes-prone animals have increased intestinal permeability $[74,76]$

\section{Human studies}

$\mathrm{T}$ cells derived from diabetic pancreas tissue adhere to mucosal endothelium [66]

GAD-reactive lymphocytes express gut-associated homing receptor [67]

Immunological activity in the small intestine is seen in diabetic patients without $\mathrm{CD}[60,61]$

Gastrointestinal alterations are found in type 1 diabetic patients [70-72]

Type 1 diabetic patients have high zonulin levels, associated with increased gut permeability [75]

Paediatric patients with type 1 diabetes, but without signs of $\mathrm{CD}$, had increased expression of MHC class II antigens and intercellular adhesion molecule 1 (ICAM-1) on the intestinal epithelium $[60,61]$. The jejunal specimens contained higher concentrations of IFN $\gamma$ - and TNF $\alpha$-positive cells, and had a higher density of IL$1 \alpha$ - and IL-4-positive cells in the lamina propria, than those of healthy controls. While IL- $1 \alpha$ is a proinflammatory cytokine secreted by monocytes and epithelial cells during intestinal inflammation, IL-4 is a Th2 cytokine, known to enhance epithelial permeability [61]. Interestingly, these findings were not restricted to patients carrying HLA-DQ2, suggesting an intestinal inflammatory response in type 1 diabetic patients, independent of a CD-associated genotype. Therefore, it seems that the gut immune system is activated in type 1 diabetic patients, and that activation is not only due to the shared genotype with $\mathrm{CD}$ patients.

In NOD mice, lymphocytes infiltrating the islets, especially during the prediabetic phase, express the GALT-specific $\alpha 4 \beta 7$ integrin [62], and antibodies blocking the $\alpha 4 \beta 7$ integrin prevent diabetes $[62,63]$. This suggests a role for the intestinal immune system in the early phases of diabetes. Moreover, it has been shown that mesenteric lymphocytes transfer diabetes from NOD mice to non-diabetic mice, which indicates that diabetogenic $\mathrm{T}$ cells are activated in the mesenteric immune system before infiltrating the pancreas [64]. Similarly, lymphocytes with diabetogenic potential isolated from 3-week-old NOD mice were found in gutassociated lymph nodes [65]. This suggests that the initial priming of diabetogenic cells takes place in the gut and that further amplification of the autoimmune response may occur in the pancreas-associated lymph nodes (PLN) [65]. Human studies also support the hypothesis that autoreactive $\mathrm{T}$ cells may originate from the intestinal immune system, as lymphocytes from diabetic pancreases were found to adhere specifically to mucosal and pancreatic endothelium [66] and GAD-reactive $\mathrm{T}$ cells from patients with type 1 diabetes were shown to express $\alpha 4 \beta 7$ integrin [67].

These findings suggest that the gut immune system is activated in patients with type 1 diabetes, and that the pancreas and the gut share the same lymphocyte recirculation pool. This supports the notion that autoreactive T cells infiltrating the pancreas could be activated in GALT. It is not clear, however, to what extent these changes are attributable to gluten.

\section{Gastrointestinal alterations in type 1 diabetes}

Changes in intestinal morphology and permeability, which may or may not involve gluten, have been recognised both in animal models of type 1 diabetes and in human patients.

BB rats have several features suggesting intestinal malfunction. These include increased intestinal permeability, changes in mucosal crypt depth, massive epithelial cell proliferation, lymphocyte infiltration, and proinflammatory activity, before the development of 
both insulitis and diabetes [68, 69]. Human studies also support the notion that gastrointestinal changes precede the onset of type 1 diabetes. In a study of patients with islet autoimmunity at different stages all patients showed an increase in intestinal permeability in a lactulose-mannitol test [70]; alterations in intestinal barrier structure and function in non-coeliac type 1 diabetic patients have also been described [71]. Likewise, HLA-DQ2-positive paediatric diabetic patients had higher intestinal permeability, which could facilitate contact of food antigens with the mucosal immune system [72]. This implies that these patients may be more prone to developing abnormal immune responses to common food antigens. It is also consistent with the development of $\mathrm{CD}$, where changes in the intestinal barrier function and tight junction structure of the jejunum of children with $\mathrm{CD}$ take place early on in the disease development [73]. The findings point to the crucial role intestinal barrier functions play in relation to both $\mathrm{CD}$ and type 1 diabetes development and, furthermore, suggest that a primary intestinal defect could exist in patients with type 1 diabetes.

The importance of changes in intestinal permeability is further supported by findings regarding changes in zonulin, a protein that opens intestinal tight junctions. In the diabetesprone BB rat, intestinal, intraluminal zonulin levels are elevated 35-fold compared with levels in the diabetes-resistant $\mathrm{BB}$ rat [74]. Likewise, $70 \%$ of type 1 diabetes at-risk subjects with elevated autoantibodies but no established disease had increased serum zonulin levels [75]. Blocking the zonulin receptor reduces diabetes incidence by $70 \%[74]$ and restoration of the impaired intestinal barrier contributes to the prevention of type 1 diabetes in $\mathrm{BB}$ rats [76]. Thus, upregulation of zonulin, with consequent increased intestinal permeability, precedes the onset of type 1 diabetes. The latter is a direct effect of gliadin, which binds to the chemokine receptor chemokine (C-X-C motif) receptor 3 (CXCR3), leading to myeloid differentiation factor 88 (MyD88)-dependent zonulin release in enterocytes [77], but factors other than gluten could influence intestinal permeability in both animal models of type 1 diabetes and patients.

These studies show that changes in intestinal morphology and permeability possibly precede development of type 1 diabetes.

\section{The effect of dietary gluten on the immune system has not been clarified}

The mechanisms by which dietary gluten influences the immune system have not been well characterised, although some studies have been performed (Text box: In vivo and in vitro studies provide evidence for a direct effect of gluten on the immune system).

\section{In vivo and in vitro studies provide evidence for a direct effect of gluten on the immune system \\ Effect of gluten intake (in vitro studies) \\ Macrophages: proinflammatory cytokine production; NO production [85, 86, 97] \\ Dendritic cells: upregulation of MHCII; maturation markers; co-stimulatory molecules; TLRs; cytokine and chemokine production $[7,8,84]$}

Effect of gluten intake (in vivo studies)

NOD mice show Th1/Th17 cytokine bias in the intestine [78, 98]

NOD mice show increased activated intestinal $\mathrm{CD}^{+} \mathrm{T}$ cells, DCs and Th17 cells [98]

BB rats show a Th1 cytokine bias in MLN [79] and intestine [55]

BB rats show a Th1 cytokine pattern in islet infiltrate [83]

Proportional changes in regulatory $\mathrm{T}$ cell subsets in BALB/c mice [81]

Increased number of Th17 cells in PLN in BALB/c mice [81]

Inflammatory cytokine pattern in $\mathrm{FOXP}^{-}$and $\mathrm{FOXP}^{+} \mathrm{T}$ cells in BALB/c mice [82]

Innate immune activation [99]

First, in NOD mice, gluten intake promotes a Th1 cytokine bias in the small intestine, compared with a semi-purified hypoallergenic diet [78]. This was confirmed in a study in young BB rats showing that a wheat-based diet induces a proinflammatory $\mathrm{Th} 1$ bias in the mesenteric lymph nodes (MLN), with a high proportion of $\mathrm{IFN} \gamma^{+} \mathrm{CD} 4^{+} \mathrm{T}$ cells that proliferate specifically in response to wheat protein antigens. In addition, abundance of the Th2 cytokine-specific transcription factor GATA3 was reduced, while no change was seen in the expression of the Th1 cytokine-specific transcription factor T-bet. This suggests that the MLN display a Th1 bias as a result of the Th2 deficit. The Th1 cytokine bias existed as early as 1 week before weaning, implying that the MLN cells were primed towards a Th1 phenotype, prior to pancreatic inflammation [79]. Conversely, BB rats fed a cereal-based diet exhibited a decreased IFN $\gamma /$ TGF $\beta$ ratio in the gut [55]. This could imply that gluten's ability to induce a Th1 cytokine profile in the gut of CD patients [80] also occurs in animal models of type 1 diabetes. Recently, we published data showing that gluten intake in BALB/c mice led to a decreased proportion of $\gamma \delta$ T cells in all lymphoid compartments studied, while the number of Th17 cells, which are associated with the development of autoimmunity, increased substantially in 
PLN [81]. Furthermore, the gluten-containing diet changed both forkhead box P3 (FOXP3) ${ }^{-}$T cells and FOXP3 ${ }^{+}$T cells, to a more inflammatory cytokine profile, with higher levels of IL-17, IL-2, IL-4 and IFN $\gamma$. In contrast, the gluten-free diet induced an anti-inflammatory cytokine profile, with higher proportions of TGF $\beta^{+} \mathrm{FOXP}^{-} \mathrm{T}$ cells in all of the tested lymphoid tissues and higher IL-10 expression within non-T cells in the spleen [82]. Besides the intestinal Th1 cytokine bias, a cereal-based diet also promoted a Th1 cytokine pattern (high IFN $\gamma$ and low IL-10 and TGF $\beta$ ) in islet infiltrates. Conversely, BB rats fed a hydrolysed, casein-based, semipurified diet had fewer islet-infiltrating cells, low IFN $\gamma$ and high levels of TGF $\beta$. The non-cereal-based diet thus protected $\mathrm{BB}$ rats from developing diabetes by inducing a noninflammatory cytokine pattern in the pancreas [83]. It is not completely understood whether the immunological changes are exclusively due to the effect of gluten or secondary to gluten-induced changes in, for example, intestinal microbiota.

Interestingly, gluten has also been shown to directly stimulate APCs. DCs derived from the bone marrow of BALB/c mice were exposed to chymotrypsin-treated gluten, which induced DC maturation with upregulation of MHC II, costimulatory molecules (CD86, CD40, CD54) and high production of MIP-2 and keratinocyte-derived cytokine (KC). DCs exposed to $100 \mu \mathrm{g} / \mathrm{ml}$ gluten showed comparable effects to DCs exposed to $10 \mathrm{ng} / \mathrm{ml}$ lipopolysaccharide, which emphasises the stimulating capacity of gluten [7]. Moreover, $\alpha-$ chymotrypsin-digested gliadin stimulated the expression of Toll-like receptors (TLRs) 4, 7 and 8, and the secretion of IFN $\alpha$ from bone marrow-derived DCs in transgenic HLADQ8 mice [84]. Human monocyte-derived DCs are also matured by gliadin. Stimulation leads to enhanced expression of CD80, CD83 and CD86, plus upregulation of HLA-DR, accompanied by an increased secretion of IL-6, IL-8, IL-10, $\mathrm{TNF} \alpha$, monocyte chemotactic protein (MCP-1) and MCP-2. After gliadin stimulation, the DCs showed reduced endocytosis and an improved capacity to stimulate the proliferation of allogeneic T cells [8]. Besides having an effect on DCs, gliadin peptides also induce murine peritoneal macrophages to express proinflammatory cytokine genes such as TNF $\alpha$, IL12 and IL-15 [85] and NO production [86]. The cytokine production was dependent on MyD88, which is a key adapter molecule in the TLR/IL-1R signalling pathway [85]. The gluten epitopes recognised by DCs and macrophages, and the exact mechanisms of recognition, remain to be clarified. However, the direct effect of gluten on APCs emphasises gluten's immunogenic properties, and shows that gluten peptides have the capacity to stimulate APCs to deliver costimulatory signals to T cells.

Interestingly, it has been shown that specific gluten peptides (e.g. p31-43) have a direct effect on the innate immune system [87]. These gluten peptides induce expression of the innate cytokines IL-15 and IFN $\alpha$ in the intestinal lamina propria $[10,88]$, altering the tolerogenic phenotype of the DCs. Moreover, these peptides also have the capacity to directly activate epithelial cells in the gut by upregulation of non-classical MHC class-I molecules (HLA-E), MIC-A and MIC-B, and induce IL-15 secretion [89, 90]. MIC serves as a ligand for the NK receptor NKG2D, which is expressed on the intraepithelial $\mathrm{CD}^{+} \mathrm{T}$ lymphocytes. The cells become socalled lymphokine-activated killer cells with NK-like cytolytic function, that is, they have the ability to kill target cells independent of $\mathrm{T}$ cell receptor ligation. These cells induce direct cytolysis of enterocytes via NKG2D-MIC engagement in patients with CD [91]. Dietary gluten is thus found to induce a Th1 cytokine bias in the gut and islet infiltrates in NOD mice and BB rats, and it seems to induce innate cell activation and maturation of APCs. Recently, it has been suggested that some of the effects of gluten proteins are not mediated by the proteins themselves, but by wheat amylase trypsin inhibitors, which furthermore activate TLR4 [92].

\section{Direct effects of gluten on pancreatic beta cells}

Gliadin not only modulates the immune system but also affects the target cells: the pancreatic beta cells. This was recently shown in vitro and in vivo using gluten digested with a range of digestive enzymes, as well as a 33-mer gliadin peptide (residues 57-89 of alpha 2-gliadin). In vitro, both stimuli increased the long-term $(24 \mathrm{~h})$, but not the short-term (30 $\mathrm{min})$, insulin secretion. It was possible to demonstrate that the effect was due to closure of the ATP-sensitive K-channels, by directly affecting the channels. In vivo, a long-term effect was also seen. NOD mice, which were injected with gliadin digest, obtained higher body weights as adults, probably reflecting the higher insulin secretion from the islets [93]. Beta cell stress can contribute to diabetes development through increased antigen expression, whereas a reduction of diabetes incidence is seen in animal models with early prophylactic insulin treatment of diabetes-prone animals [94].

\section{Conclusion}

The present review describes the findings and development of our knowledge over the last decades on the connection between gluten and the pathogenesis of type 1 diabetes. The studies have primarily focused on describing incidence of type 1 diabetes in relation to the timing of introducing gluten into the diet, and the influence of gluten on the intestinal flora and the immune system. Most important is to evaluate the effect of a gluten-free diet on human type 1 diabetes: in this regard, a promising case has been published. In the future, the balance between the innate and adaptive immune systems must be clarified. The research field covering gluten, diet and type 1 
diabetes has proven surprisingly interesting and requires further attention.

Funding This work was supported by a grant from Kirsten and Freddy Johansens Fond. DPF was supported by Institutional Research Concept RVO: 61388971 and grant no. 310/09/1640 from the Grant Agency of the Czech Republic.

Duality of interest The authors declare that there is no duality of interest associated with this manuscript.

Contribution statement JCA was responsible for data collection, conception, design and writing of the paper. KJ contributed to drafting and revision of the paper. DPF, KB and KE revised the manuscript. All authors approved the version to be published.

Open Access This article is distributed under the terms of the Creative Commons Attribution License which permits any use, distribution, and reproduction in any medium, provided the original author(s) and the source are credited.

\section{References}

1. Eurodiab, ACE Study Group (2000) Variation and trends in incidence of childhood diabetes in Europe. Lancet 355:873-876

2. Akerblom HK, Vaarala O, Hyoty H, Ilonen J, Knip M (2002) Environmental factors in the etiology of type 1 diabetes. Am J Med Genet 115:18-29

3. Strachan DP (1989) Hay fever, hygiene, and household size. BMJ 299:1259-1260

4. Jabri B, Sollid LM (2009) Tissue-mediated control of immunopathology in coeliac disease. Nat Rev Immunol 9:858-870

5. Fasano A, Berti I, Gerarduzzi T et al (2003) Prevalence of celiac disease in at-risk and not-at-risk groups in the United States: a large multicenter study. Arch Intern Med 163:286-292

6. Shan L, Molberg O, Parrot I et al (2002) Structural basis for gluten intolerance in celiac sprue. Science 297:2275-2279

7. Nikulina M, Habich C, Flohe SB, Scott FW, Kolb H (2004) Wheat gluten causes dendritic cell maturation and chemokine secretion. J Immunol 173:1925-1933

8. Palova-Jelinkova L, Rozkova D, Pecharova B et al (2005) Gliadin fragments induce phenotypic and functional maturation of human dendritic cells. J Immunol 175:7038-7045

9. Sollid LM (2000) Molecular basis of celiac disease. Annu Rev Immunol 18:53-81

10. Maiuri L, Ciacci C, Ricciardelli I et al (2003) Association between innate response to gliadin and activation of pathogenic $\mathrm{T}$ cells in coeliac disease. Lancet 362:30-37

11. Smyth DJ, Plagnol V, Walker NM et al (2008) Shared and distinct genetic variants in type 1 diabetes and celiac disease. N Engl J Med 359:2767-2777

12. Collin P, Kaukinen K, Valimaki M, Salmi J (2002) Endocrinological disorders and celiac disease. Endocr Rev 23:464 483

13. Hansen D, Brock-Jacobsen B, Lund E et al (2006) Clinical benefit of a gluten-free diet in type 1 diabetic children with screening-detected celiac disease: a population-based screening study with 2 years' follow-up. Diabetes Care 29:2452-2456

14. Cosnes J, Cellier C, Viola S et al (2008) Incidence of autoimmune diseases in celiac disease: protective effect of the gluten-free diet. Clin Gastroenterol Hepatol 6:753-758
15. Shewry PR, Halford NG, Belton PS, Tatham AS (2002) The structure and properties of gluten: an elastic protein from wheat grain. Philos Trans R Soc Lond B Biol Sci 357:133-142

16. Shewry PR, Halford NG (2002) Cereal seed storage proteins: structures, properties and role in grain utilization. J Exp Bot 53:947-958

17. Piper JL, Gray GM, Khosla C (2004) Effect of prolyl endopeptidase on digestive-resistant gliadin peptides in vivo. J Pharmacol Exp Ther 311:213-219

18. Helmerhorst EJ, Zamakhchari M, Schuppan D, Oppenheim FG (2010) Discovery of a novel and rich source of gluten-degrading microbial enzymes in the oral cavity. PLoS One 5:e13264

19. Bernardo D, Garrote JA, Nadal I et al (2009) Is it true that coeliacs do not digest gliadin? Degradation pattern of gliadin in coeliac disease small intestinal mucosa. Gut 58:886-887

20. Nadal I, Donat E, Ribes-Koninckx C, Calabuig M, Sanz Y (2007) Imbalance in the composition of the duodenal microbiota of children with coeliac disease. J Med Microbiol 56:1669-1674

21. Tlaskalova-Hogenova H, Stepankova R, Farre M et al (1997) Autoimmune reactions induced by gliadin feeding in germ-free AVN rats and athymic nude mice. Animal models for celiac disease. Ann N Y Acad Sci 815:503-505

22. Stepankova R, Tlaskalova-Hogenova H, Sinkora J, Jodl J, Fric P (1996) Changes in jejunal mucosa after long-term feeding of germfree rats with gluten. Scand J Gastroenterol 31:551-557

23. Pozzilli P, Signore A, Williams AJ, Beales PE (1993) NOD mouse colonies around the world - recent facts and figures. Immunol Today 14:193-196

24. Buschard K, Pedersen C, Hansen SV, Hageman I, Aaen K, Bendtzen K (1992) Anti-diabetogenic effect of fusidic acid in diabetes prone BB rats. Autoimmunity 14:101-104

25. Hansen CH, Krych L, Nielsen DS et al (2012) Early life treatment with vancomycin propagates Akkermansia muciniphila and reduces diabetes incidence in the NOD mouse. Diabetologia 55: 2285-2294

26. Matsuzaki T, Nagata Y, Kado S et al (1997) Prevention of onset in an insulin-dependent diabetes mellitus model, NOD mice, by oral feeding of Lactobacillus casei. APMIS 105:643-649

27. Wen L, Ley RE, Volchkov PY et al (2008) Innate immunity and intestinal microbiota in the development of type 1 diabetes. Nature 455:1109-1113

28. Hansen AK, Ling F, Kaas A, Funda DP, Farlov H, Buschard K (2006) Diabetes preventive gluten-free diet decreases the number of caecal bacteria in non-obese diabetic mice. Diabetes Metab Res Rev 22:220-225

29. Marietta EV, Gomez AM, Yeoman C et al (2013) Low incidence of spontaneous type 1 diabetes in non-obese diabetic mice raised on gluten-free diets is associated with changes in the intestinal microbiome. PLoS One 8:e78687

30. Patrick C, Wang GS, Lefebvre DE et al (2013) Promotion of autoimmune diabetes by cereal diet in the presence or absence of microbes associated with gut immune activation, regulatory imbalance, and altered cathelicidin antimicrobial peptide. Diabetes 62:2036-2047

31. Funda DP, Kaas A, Bock T, Tlaskalova-Hogenova H, Buschard K (1999) Gluten-free diet prevents diabetes in NOD mice. Diabetes Metab Res Rev 15:323-327

32. Funda DP, Kaas A, Tlaskalova-Hogenova H, Buschard K (2008) Gluten-free but also gluten-enriched (gluten+) diet prevent diabetes in NOD mice; the gluten enigma in type 1 diabetes. Diabetes Metab Res Rev 24:59-63

33. Hoorfar J, Scott FW, Cloutier HE (1991) Dietary plant materials and development of diabetes in the BB rat. J Nutr 121:908-916

34. Coleman DL, Kuzava JE, Leiter EH (1990) Effect of diet on incidence of diabetes in nonobese diabetic mice. Diabetes 39:432-436

35. Scott FW (1996) Food-induced type 1 diabetes in the BB rat. Diabetes Metab Rev 12:341-359 
36. Pastore MR, Bazzigaluppi E, Belloni C, Arcovio C, Bonifacio E, Bosi E (2003) Six months of gluten-free diet do not influence autoantibody titers, but improve insulin secretion in subjects at high risk for type 1 diabetes. J Clin Endocrinol Metab 88:162-165

37. Fuchtenbusch M, Ziegler AG, Hummel M (2004) Elimination of dietary gluten and development of type 1 diabetes in high risk subjects. Rev Diabet Stud 1:39-41

38. Sildorf SM, Fredheim S, Svensson J, Buschard K (2012) Remission without insulin therapy on gluten-free diet in a 6-year old boy with type 1 diabetes mellitus. BMJ Case Rep. doi:10.1136/bcr.02.2012.5878

39. Saadah OI, Zacharin M, O'Callaghan A, Oliver MR, Catto-Smith AG (2004) Effect of gluten-free diet and adherence on growth and diabetic control in diabetics with coeliac disease. Arch Dis Child 89:871-876

40. Rami B, Sumnik Z, Schober E et al (2005) Screening detected celiac disease in children with type 1 diabetes mellitus: effect on the clinical course (a case control study). J Pediatr Gastroenterol Nutr 41:317-321

41. Westman E, Ambler GR, Royle M, Peat J, Chan A (1999) Children with coeliac disease and insulin dependent diabetes mellitusgrowth, diabetes control and dietary intake. J Pediatr Endocrinol Metab 12:433-442

42. Troncone R, Franzese A, Mazzarella G et al (2003) Gluten sensitivity in a subset of children with insulin dependent diabetes mellitus. Am J Gastroenterol 98:590-595

43. Mojibian M, Chakir H, Lefebvre DE et al (2009) Diabetes-specific HLA-DR-restricted proinflammatory $\mathrm{T}$ cell response to wheat polypeptides in tissue transglutaminase antibody-negative patients with type 1 diabetes. Diabetes 58:1789-1796

44. Klemetti P, Savilahti E, Ilonen J, Akerblom HK, Vaarala O (1998) T cell reactivity to wheat gluten in patients with insulin-dependent diabetes mellitus. Scand J Immunol 47:48-53

45. MacFarlane AJ, Burghardt KM, Kelly J et al (2003) A type 1 diabetes-related protein from wheat (Triticum aestivum): cDNA clone of a wheat storage globulin, Glb1, linked to islet damage. J Biol Chem 278:54-63

46. Simpson M, Mojibian M, Barriga K et al (2009) An exploration of Glo-3A antibody levels in children at increased risk for type 1 diabetes mellitus. Pediatr Diabetes 10:563-572

47. Mueller DB, Koczwara K, Mueller AS, Pallauf J, Ziegler AG, Bonifacio E (2009) Influence of early nutritional components on the development of murine autoimmune diabetes. Ann Nutr Metab 54:208-217

48. Ziegler AG, Schmid S, Huber D, Hummel M, Bonifacio E (2003) Early infant feeding and risk of developing type 1 diabetes-associated autoantibodies. JAMA 290:1721-1728

49. Norris JM, Barriga K, Klingensmith $\mathrm{G}$ et al (2003) Timing of initial cereal exposure in infancy and risk of islet autoimmunity. JAMA 290:1713-1720

50. Atkinson M, Gale EA (2003) Infant diets and type 1 diabetes: too early, too late, or just too complicated? JAMA 290:1771-1772

51. Strobel S, Mowat AM (1998) Immune responses to dietary antigens: oral tolerance. Immunol Today 19:173-181

52. Hummel S, Pfluger M, Hummel M, Bonifacio E, Ziegler AG (2011) Primary dietary intervention study to reduce the risk of islet autoimmunity in children at increased risk for type 1 diabetes: the BABYDIET study. Diabetes Care 34:1301-1305

53. Ludvigsson J (2003) Cow-milk-free diet during last trimester of pregnancy does not influence diabetes-related autoantibodies in nondiabetic children. Ann N Y Acad Sci 1005:275-278

54. Virtanen SM, Takkinen HM, Nevalainen J et al (2011) Early introduction of root vegetables in infancy associated with advanced $\beta$-cell autoimmunity in young children with human leukocyte antigenconferred susceptibility to type 1 diabetes. Diabet Med 28:965-971

55. Scott FW, Rowsell P, Wang GS, Burghardt K, Kolb H, Flohe S (2002) Oral exposure to diabetes-promoting food or immunomodulators in neonates alters gut cytokines and diabetes. Diabetes 51:73-78
56. Schmid S, Koczwara K, Schwinghammer S, Lampasona V, Ziegler AG, Bonifacio E (2004) Delayed exposure to wheat and barley proteins reduces diabetes incidence in non-obese diabetic mice. Clin Immunol 111:108-118

57. Ivarsson A, Persson LA, Nystrom L et al (2000) Epidemic of coeliac disease in Swedish children. Acta Paediatr 89:165-171

58. Ivarsson A, Hernell O, Stenlund H, Persson LA (2002) Breastfeeding protects against celiac disease. Am J Clin Nutr 75:914-921

59. Kimpimaki T, Erkkola M, Korhonen S et al (2001) Short-term exclusive breastfeeding predisposes young children with increased genetic risk of type I diabetes to progressive beta-cell autoimmunity. Diabetologia 44:63-69

60. Savilahti E, Ormala T, Saukkonen T et al (1999) Jejuna of patients with insulin-dependent diabetes mellitus (IDDM) show signs of immune activation. Clin Exp Immunol 116:70-77

61. Westerholm-Ormio M, Vaarala O, Pihkala P, Ilonen J, Savilahti E (2003) Immunologic activity in the small intestinal mucosa of pediatric patients with type 1 diabetes. Diabetes 52:2287-2295

62. Hanninen A, Salmi M, Simell O, Jalkanen S (1996) Mucosaassociated (beta 7-integrin high) lymphocytes accumulate early in the pancreas of NOD mice and show aberrant recirculation behavior. Diabetes 45:1173-1180

63. Yang XD, Sytwu HK, McDevitt HO, Michie SA (1997) Involvement of beta 7 integrin and mucosal addressin cell adhesion molecule-1 (MAdCAM-1) in the development of diabetes in obese diabetic mice. Diabetes 46:1542-1547

64. Hanninen A, Jaakkola I, Jalkanen S (1998) Mucosal addressin is required for the development of diabetes in nonobese diabetic mice. J Immunol 160:6018-6025

65. Jaakkola I, Jalkanen S, Hanninen A (2003) Diabetogenic T cells are primed both in pancreatic and gut-associated lymph nodes in NOD mice. Eur J Immunol 33:3255-3264

66. Hanninen A, Salmi M, Simell O, Jalkanen S (1993) Endothelial cellbinding properties of lymphocytes infiltrated into human diabetic pancreas. Implications for pathogenesis of IDDM. Diabetes 42:1656-1662

67. Paronen J, Klemetti P, Kantele JM et al (1997) Glutamate decarboxylase-reactive peripheral blood lymphocytes from patients with IDDM express gut-specific homing receptor $\alpha 4 \beta 7$-integrin. Diabetes 46:583-588

68. Neu J, Reverte CM, Mackey AD et al (2005) Changes in intestinal morphology and permeability in the biobreeding rat before the onset of type 1 diabetes. J Pediatr Gastroenterol Nutr 40:589-595

69. Graham S, Courtois P, Malaisse WJ, Rozing J, Scott FW, Mowat AM (2004) Enteropathy precedes type 1 diabetes in the BB rat. Gut 53:1437-1444

70. Bosi E, Molteni L, Radaelli MG et al (2006) Increased intestinal permeability precedes clinical onset of type 1 diabetes. Diabetologia 49:2824-2827

71. Secondulfo M, Iafusco D, Carratu R et al (2004) Ultrastructural mucosal alterations and increased intestinal permeability in nonceliac, type I diabetic patients. Dig Liver Dis 36:35-45

72. Kuitunen M, Saukkonen T, Ilonen J, Akerblom HK, Savilahti E (2002) Intestinal permeability to mannitol and lactulose in children with type 1 diabetes with the HLA-DQB $1 * 02$ allele. Autoimmunity 35:365-368

73. Fasano A, Not T, Wang W et al (2000) Zonulin, a newly discovered modulator of intestinal permeability, and its expression in coeliac disease. Lancet 355:1518-1519

74. Watts T, Berti I, Sapone A et al (2005) Role of the intestinal tight junction modulator zonulin in the pathogenesis of type I diabetes in BB diabetic-prone rats. Proc Natl Acad Sci U S A 102:2916-2921

75. Sapone A, de Magistris L, Pietzak M et al (2006) Zonulin upregulation is associated with increased gut permeability in subjects with type 1 diabetes and their relatives. Diabetes 55: 1443-1449 
76. Visser JT, Lammers K, Hoogendijk A et al (2010) Restoration of impaired intestinal barrier function by the hydrolysed casein diet contributes to the prevention of type 1 diabetes in the diabetesprone BioBreeding rat. Diabetologia 53:2621-2628

77. Lammers KM, Lu R, Brownley J et al (2008) Gliadin induces an increase in intestinal permeability and zonulin release by binding to the chemokine receptor CXCR3. Gastroenterology 135:194-204

78. Flohe SB, Wasmuth HE, Kerad JB et al (2003) A wheat-based, diabetes-promoting diet induces a Th1-type cytokine bias in the gut of NOD mice. Cytokine 21:149-154

79. Chakir H, Lefebvre DE, Wang H, Caraher E, Scott FW (2005) Wheat protein-induced proinflammatory $\mathrm{T}$ helper 1 bias in mesenteric lymph nodes of young diabetes-prone rats. Diabetologia 48:1576-1584

80. Nilsen EM, Jahnsen FL, Lundin KE et al (1998) Gluten induces an intestinal cytokine response strongly dominated by interferon gamma in patients with celiac disease. Gastroenterology 115:551-563

81. Antvorskov JC, Fundova P, Buschard K, Funda DP (2012) Impact of dietary gluten on regulatory T cells and Th17 cells in BALB/c mice. PLoS One 7:e33315

82. Antvorskov JC, Fundova P, Buschard K, Funda DP (2013) Dietary gluten alters the balance of pro-inflammatory and antiinflammatory cytokines in $\mathrm{T}$ cells of $\mathrm{BALB} / \mathrm{c}$ mice. Immunology 138:23-33

83. Scott FW, Cloutier HE, Kleemann R et al (1997) Potential mechanisms by which certain foods promote or inhibit the development of spontaneous diabetes in $\mathrm{BB}$ rats: dose, timing, early effect on islet area, and switch in infiltrate from Th1 to Th2 cells. Diabetes 46:589-598

84. Ciccocioppo R, Rossi M, Pesce I et al (2008) Effects of gliadin stimulation on bone marrow-derived dendritic cells from HLADQ8 transgenic MICE. Dig Liver Dis 40:927-935

85. Thomas KE, Sapone A, Fasano A, Vogel SN (2006) Gliadin stimulation of murine macrophage inflammatory gene expression and intestinal permeability are MyD88-dependent: role of the innate immune response in celiac disease. J Immunol 176:2512-2521

86. Tuckova L, Flegelova Z, Tlaskalova-Hogenova H, Zidek Z (2000) Activation of macrophages by food antigens: enhancing effect of gluten on nitric oxide and cytokine production. J Leukoc Biol 67:312-318

87. Gianfrani C, Auricchio S, Troncone R (2005) Adaptive and innate immune responses in celiac disease. Immunol Lett 99:141-145
88. Di SA, Pickard KM, Gordon JN et al (2007) Evidence for the role of interferon-alfa production by dendritic cells in the Th1 response in celiac disease. Gastroenterology 133:1175-1187

89. Hue S, Mention JJ, Monteiro RC et al (2004) A direct role for NKG2D/MICA interaction in villous atrophy during celiac disease. Immunity 21:367-377

90. Terrazzano G, Sica M, Gianfrani C et al (2007) Gliadin regulates the NK-dendritic cell cross-talk by HLA-E surface stabilization. J Immunol 179:372-381

91. Meresse B, Chen Z, Ciszewski C et al (2004) Coordinated induction by IL15 of a TCR-independent NKG2D signaling pathway converts CTL into lymphokine-activated killer cells in celiac disease. Immunity 21:357-366

92. Junker Y, Zeissig S, Kim SJ et al (2012) Wheat amylase trypsin inhibitors drive intestinal inflammation via activation of toll-like receptor 4. J Exp Med 209:2395-2408

93. Dall M, Calloe K, Haupt-Jorgensen M et al (2013) Gliadin fragments and a specific gliadin 33-mer peptide close KATP channels and induce insulin secretion in INS-1E cells and rat islets of Langerhans. PLoS One 8:e66474

94. Gotfredsen CF, Buschard K, Frandsen EK (1985) Reduction of diabetes incidence of BB Wistar rats by early prophylactic insulin treatment of diabetes-prone animals. Diabetologia 28:933-935

95. Hardin JA, Donegan L, Woodman RC, Trevenen C, Gall DG (2002) Mucosal inflammation in a genetic model of spontaneous type I diabetes mellitus. Can J Physiol Pharmacol 80:1064-1070

96. Meddings JB, Jarand J, Urbanski SJ, Hardin J, Gall DG (1999) Increased gastrointestinal permeability is an early lesion in the spontaneously diabetic BB rat. Am J Physiol 276:G951-G957

97. Tuckova L, Novotna J, Novak P et al (2002) Activation of macrophages by gliadin fragments: isolation and characterization of active peptide. J Leukoc Biol 71:625-631

98. Alam C, Valkonen S, Palagani V, Jalava J, Eerola E, Hanninen A (2010) Inflammatory tendencies and overproduction of IL-17 in the colon of young NOD mice are counteracted with diet change. Diabetes 59:2237-2246

99. Bernardo D, Garrote JA, Fernandez-Salazar L, Riestra S, Arranz E (2007) Is gliadin really safe for non-coeliac individuals? Production of interleukin 15 in biopsy culture from non-coeliac individuals challenged with gliadin peptides. Gut 56:889-890 